\section{Michigan Technological 18 8 5 University}

Michigan Technological University Digital Commons @ Michigan Tech

Global Conference of the Youth Environmental Alliance in Higher Education

Dec 9th, 2:36 PM - 2:47 PM

\title{
Session 1E Future Pathways for Action for Climate Empowerment (ACE)
}

Alessandro Caprini

Aneeqah Tariq

Cecilia Consalvo

Max van Deursen

Sofie de Wit

Follow this and additional works at: https://digitalcommons.mtu.edu/yeah-conference

\section{Recommended Citation}

Caprini, Alessandro; Tariq, Aneeqah; Consalvo, Cecilia; van Deursen, Max; and de Wit, Sofie, "Session 1E Future Pathways for Action for Climate Empowerment (ACE)" (2020). Global Conference of the Youth Environmental Alliance in Higher Education. 22.

https://doi.org/10.37099/mtu.dc.yeah-conference/2020/all-events/22 


\section{Future Pathways for Action for Climate Empowerment}

How to direct future efforts relating to ACE to effectively contribute to the ultimate objective of the UNFCCC 


\section{What is ACE?}

- Article 6 UNFCCC

- Article 12 Paris agreement

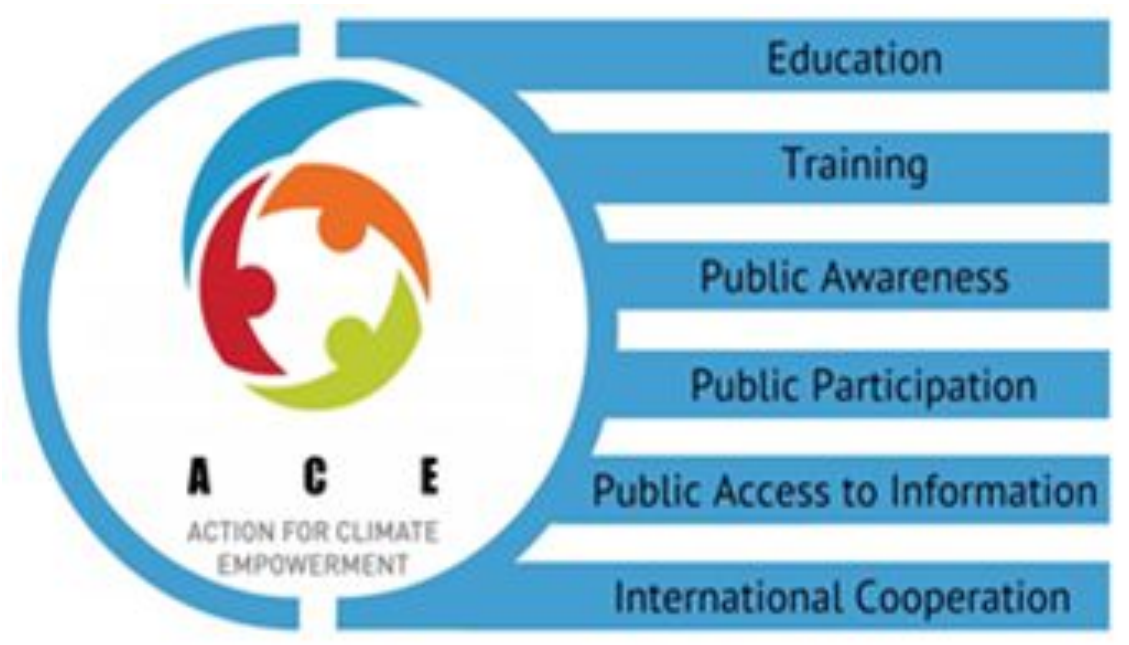




\section{Project Creation}

- ACE implementation facilitated through UNFCCC work programs

- Doha Work Program terminates in 2020

- Project commissioned by sustainable development practitioners

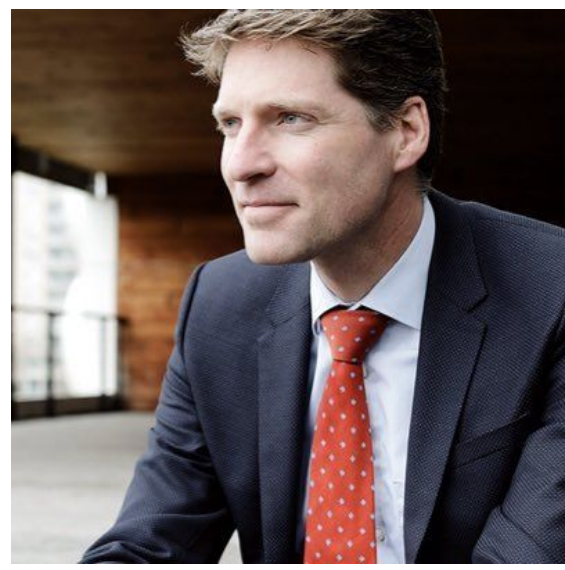

Climate Envoy for the Ministry of economic affairs and Climate
迅 $n j r$
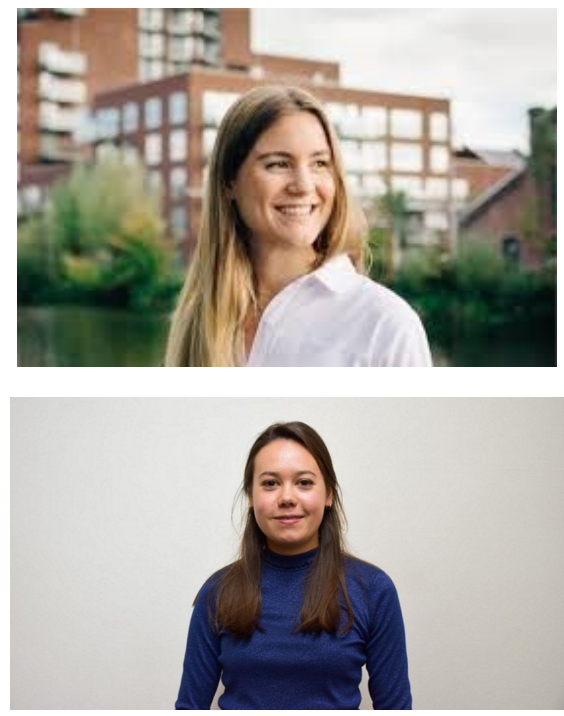

Youth Representatives on Sustainable Development to the UN 


\section{Project goals}

- Conceptualization

- Evaluation

- Developing Strategy

\&

Recommendations 


\section{"A ship in harbor is safe, but that is not what ships are built for" \\ John A. Shedd}


Competing Narratives in Climate Governance

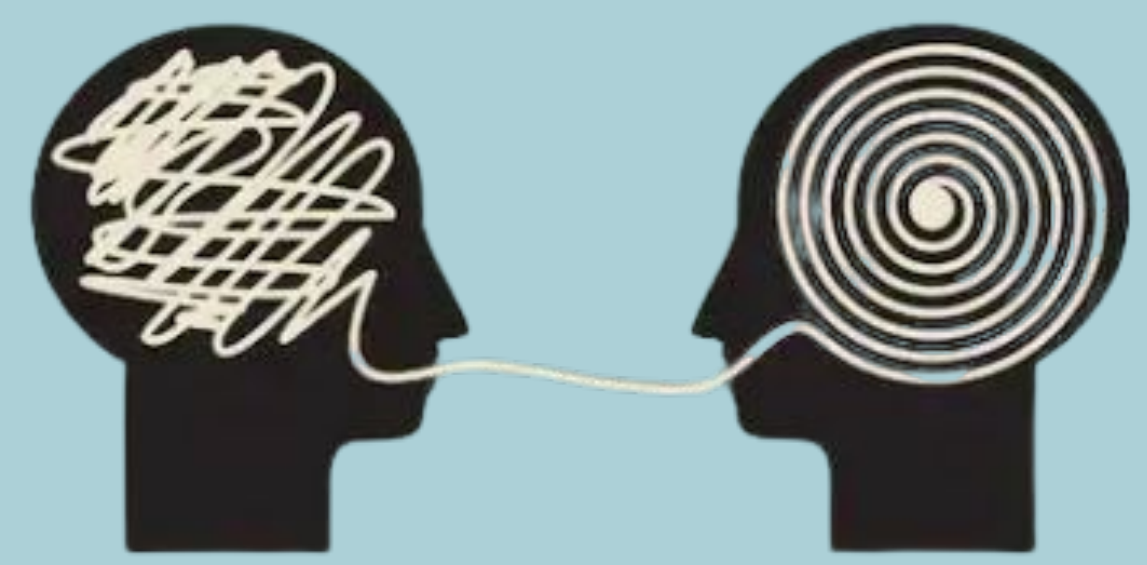




\section{Competing narratives in climate governance}

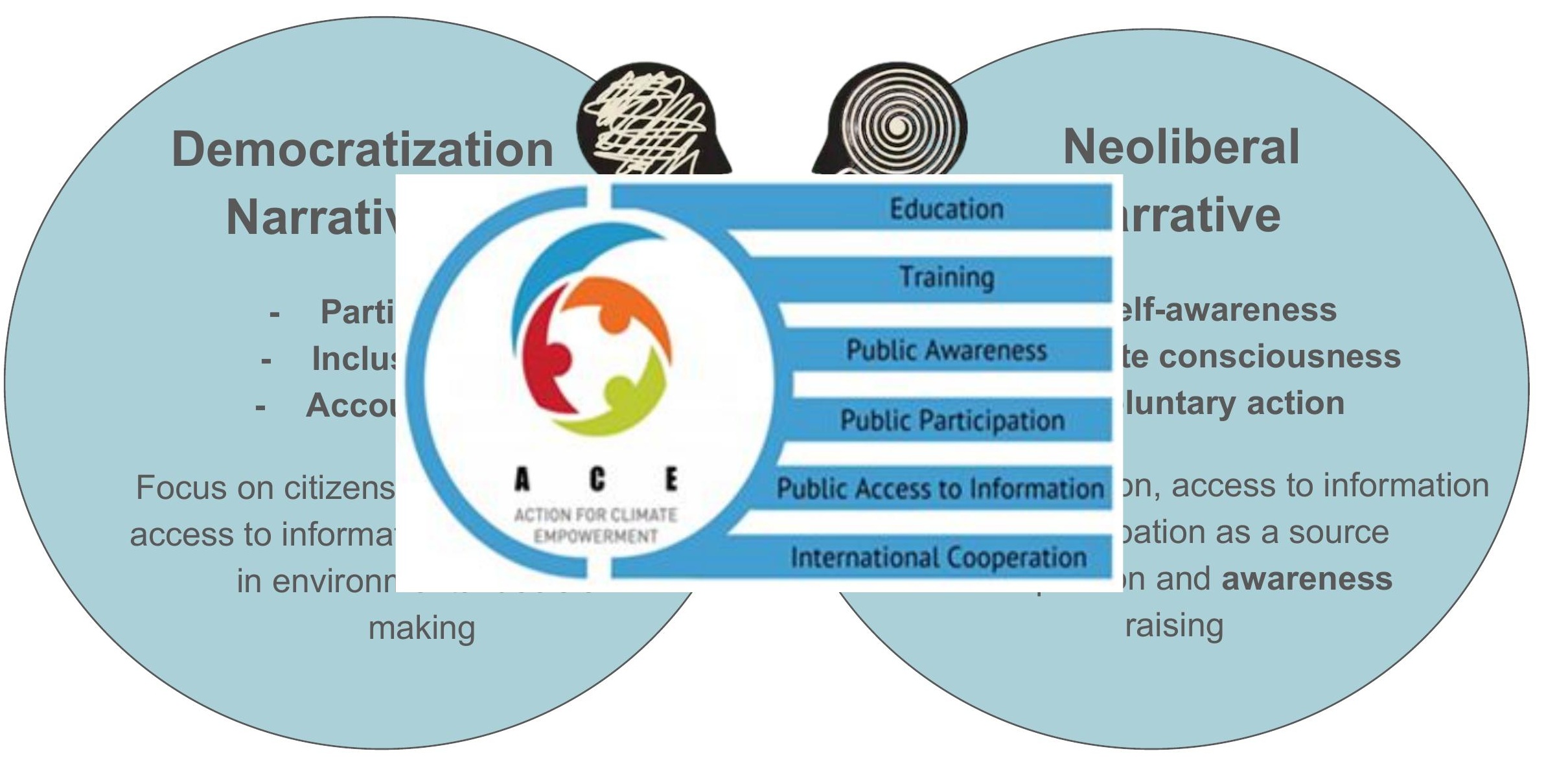




\section{Narrative-based meaning of key concepts of ACE}

\section{Empowerment}

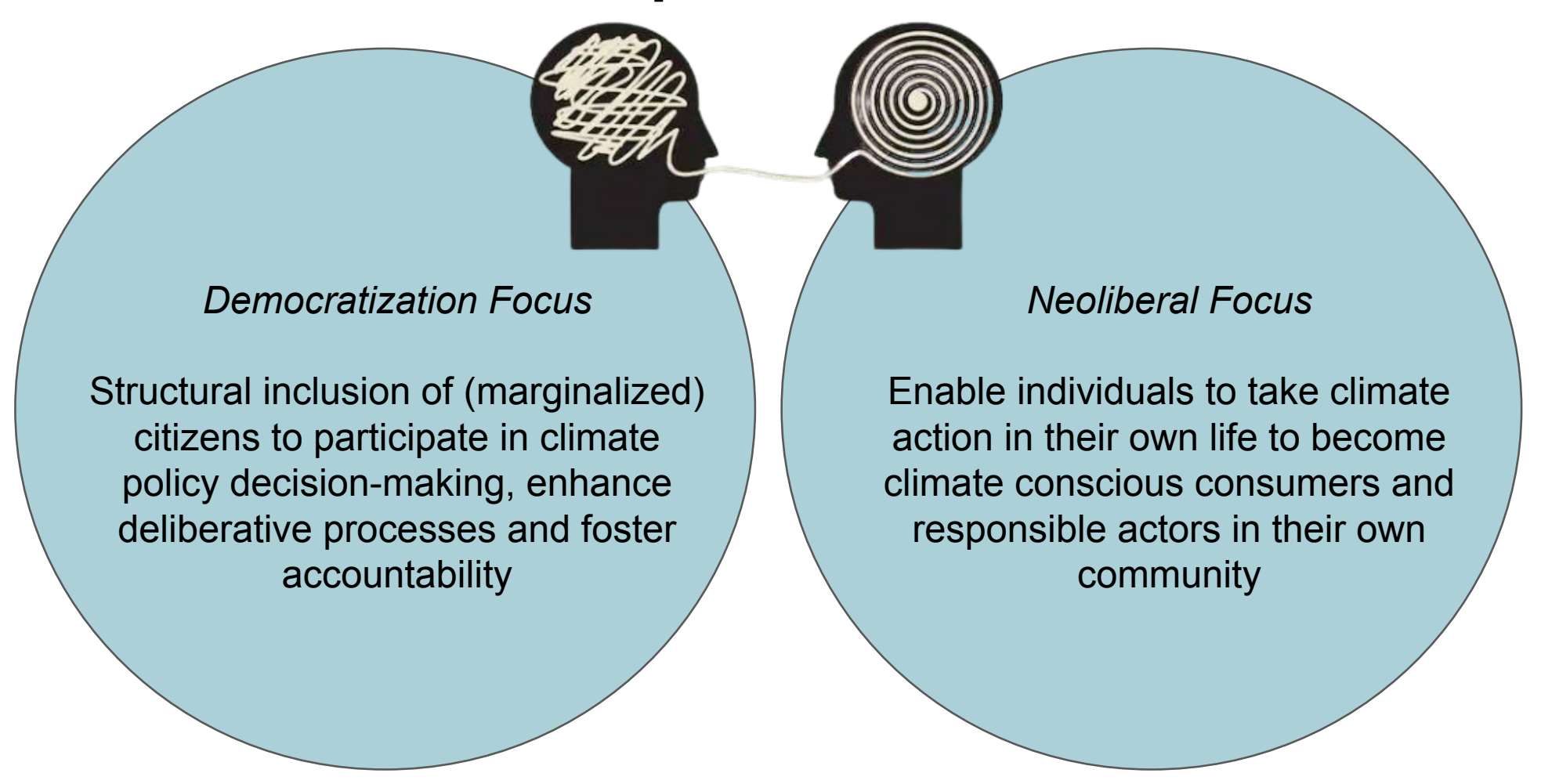




\section{Examples of Unbalanced ACE Implementation}
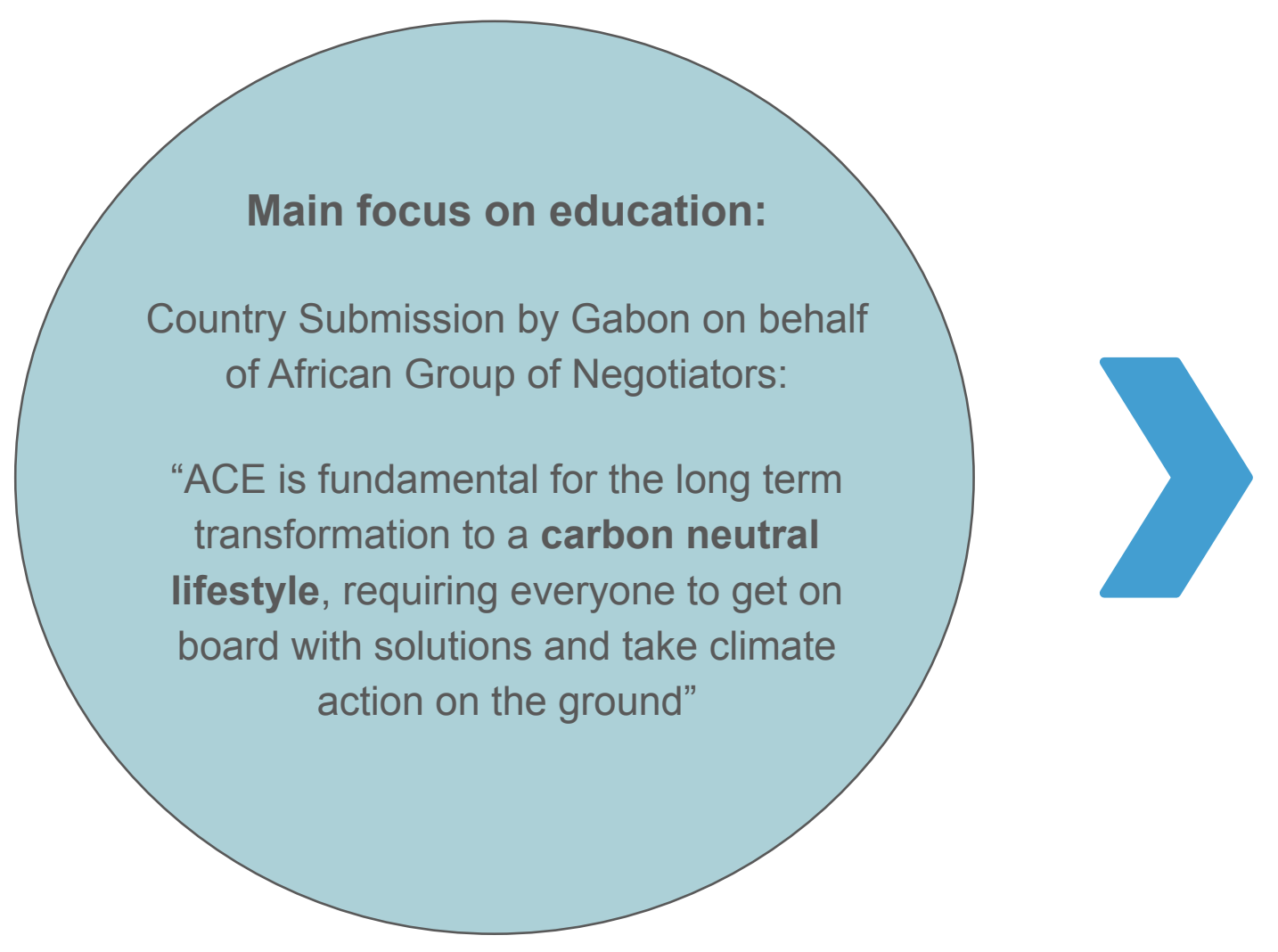

Why do these countries promote a change towards carbon neutral lifestyles, while they have some of the lowest per capita emissions? 


\section{Key Challenges ACE}

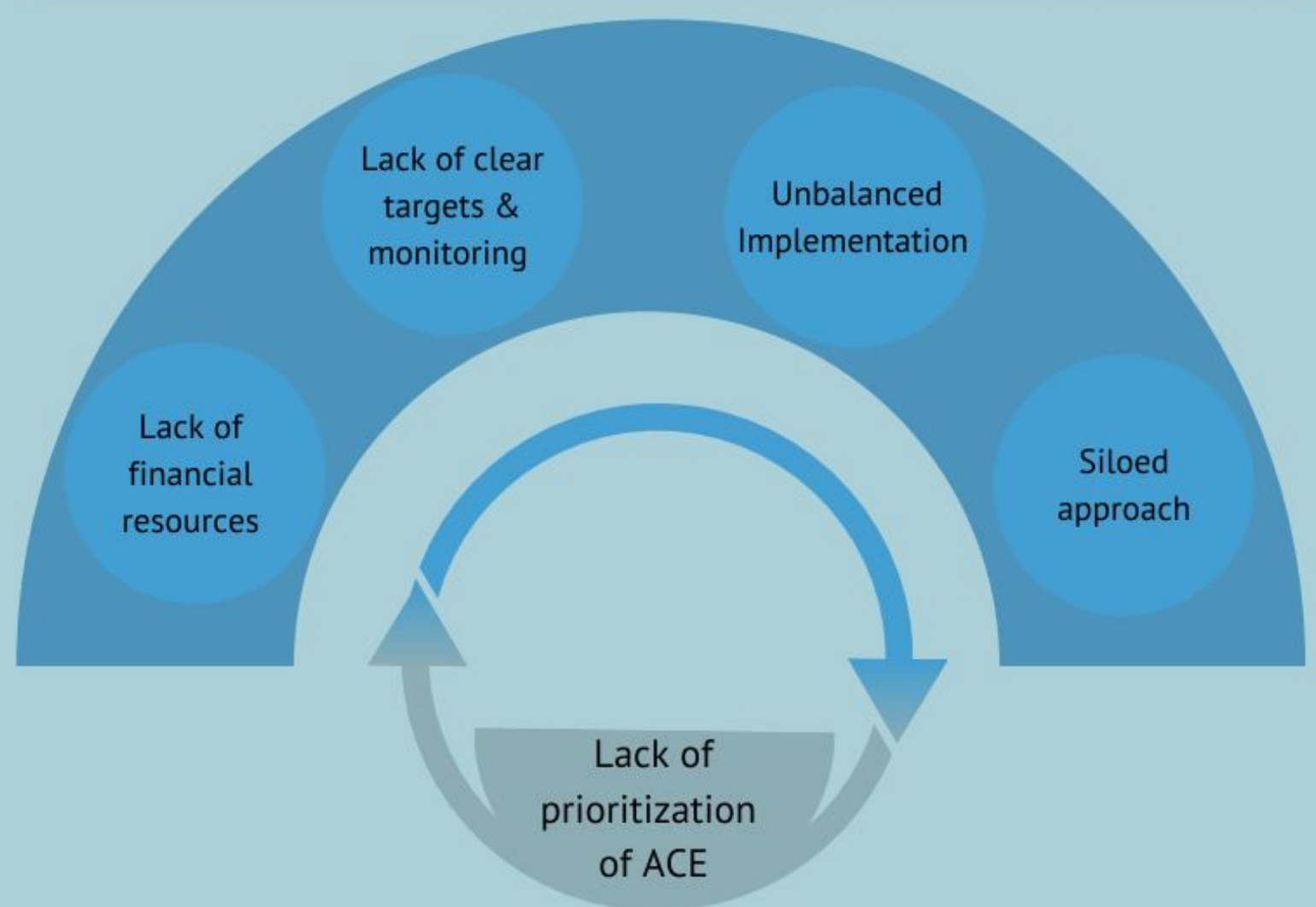




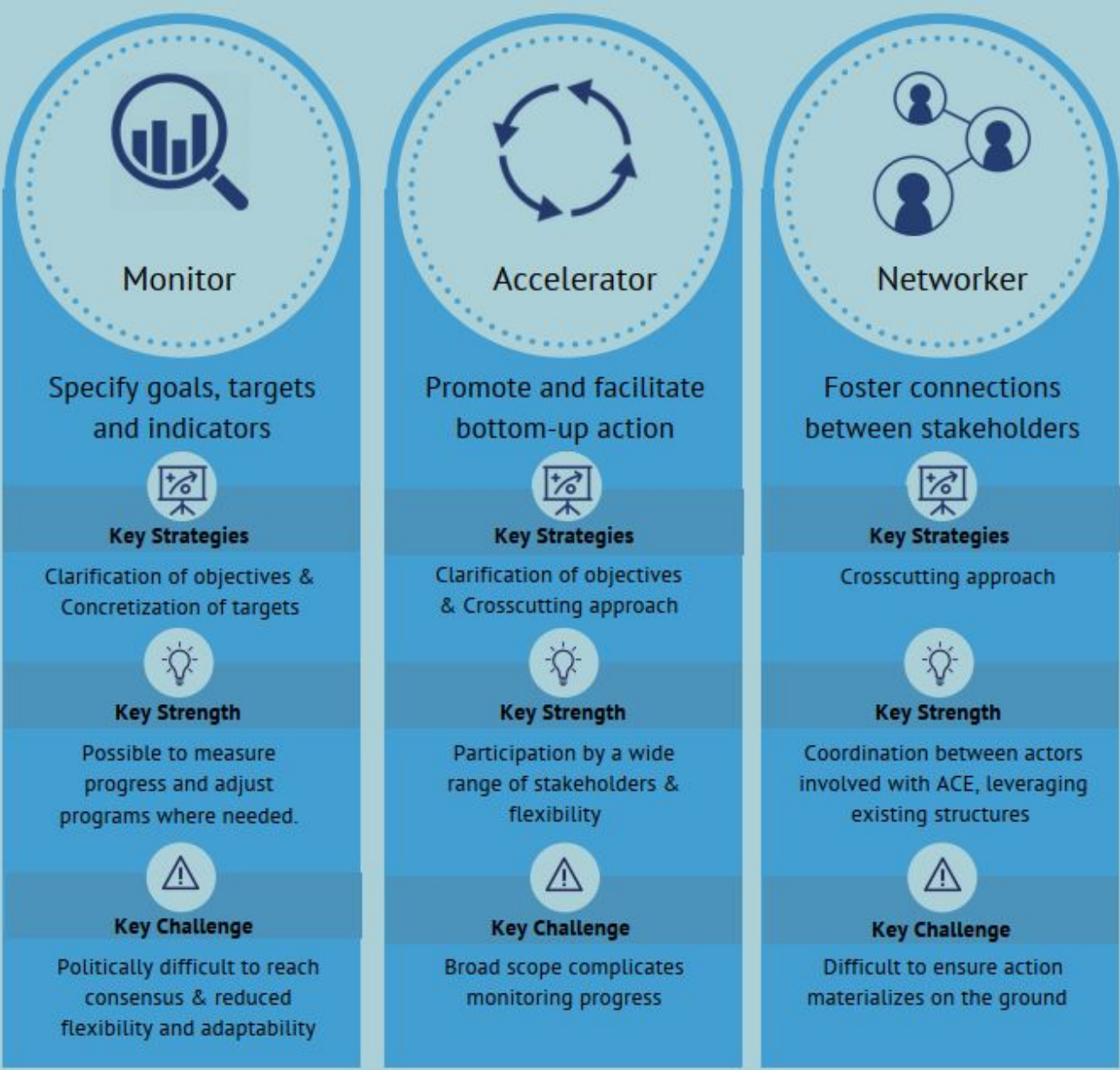




\section{Follow through}

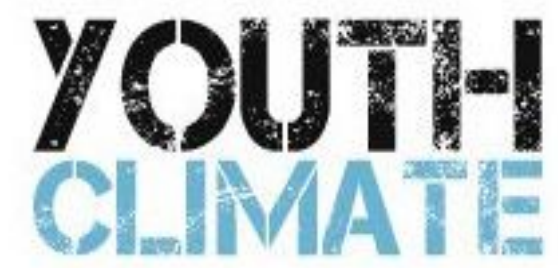

YOUNGO ACE working group

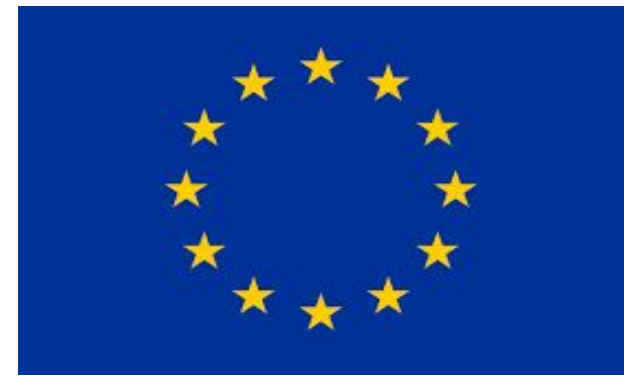

EU ACE group of negotiators

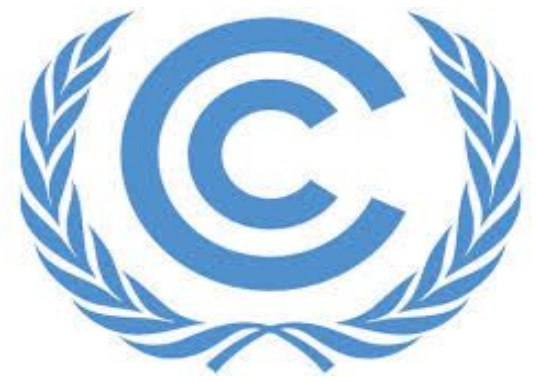

UNFCCC secretariat 


\section{Impact \& Roadmap}

20/10/20:

Finish ACE

policy brief
2021:

SB52
局 Document

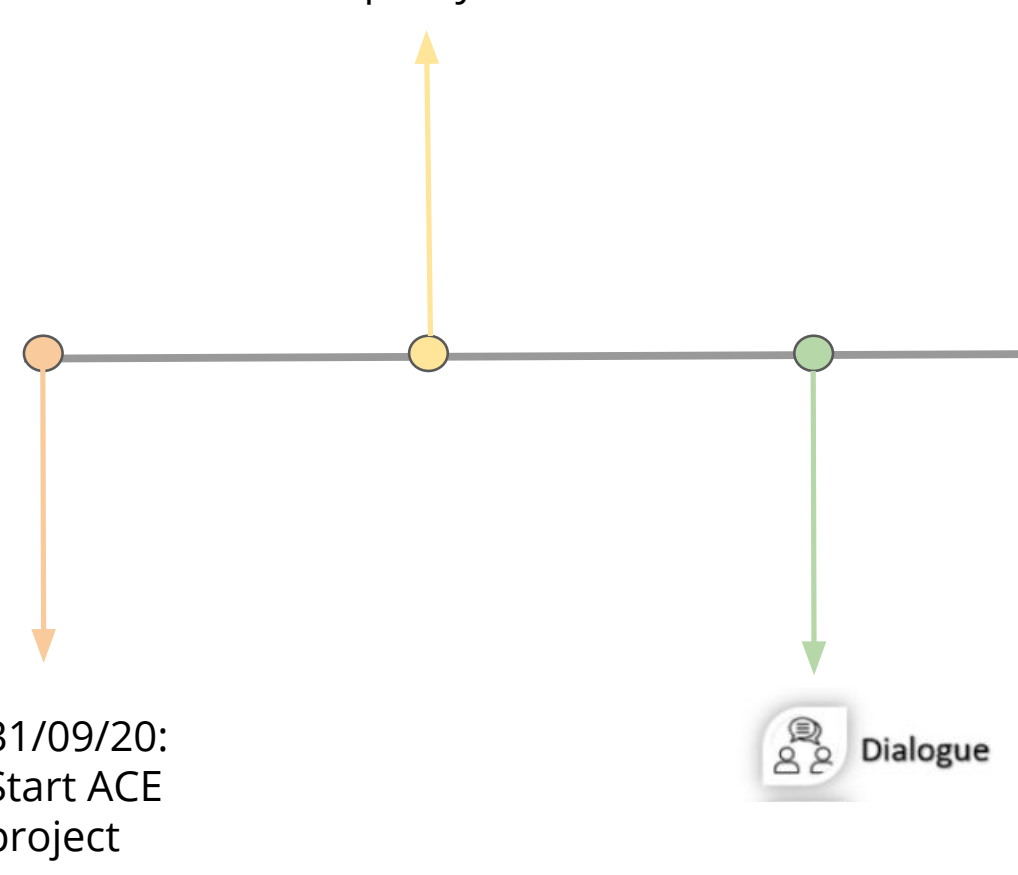


Questions?

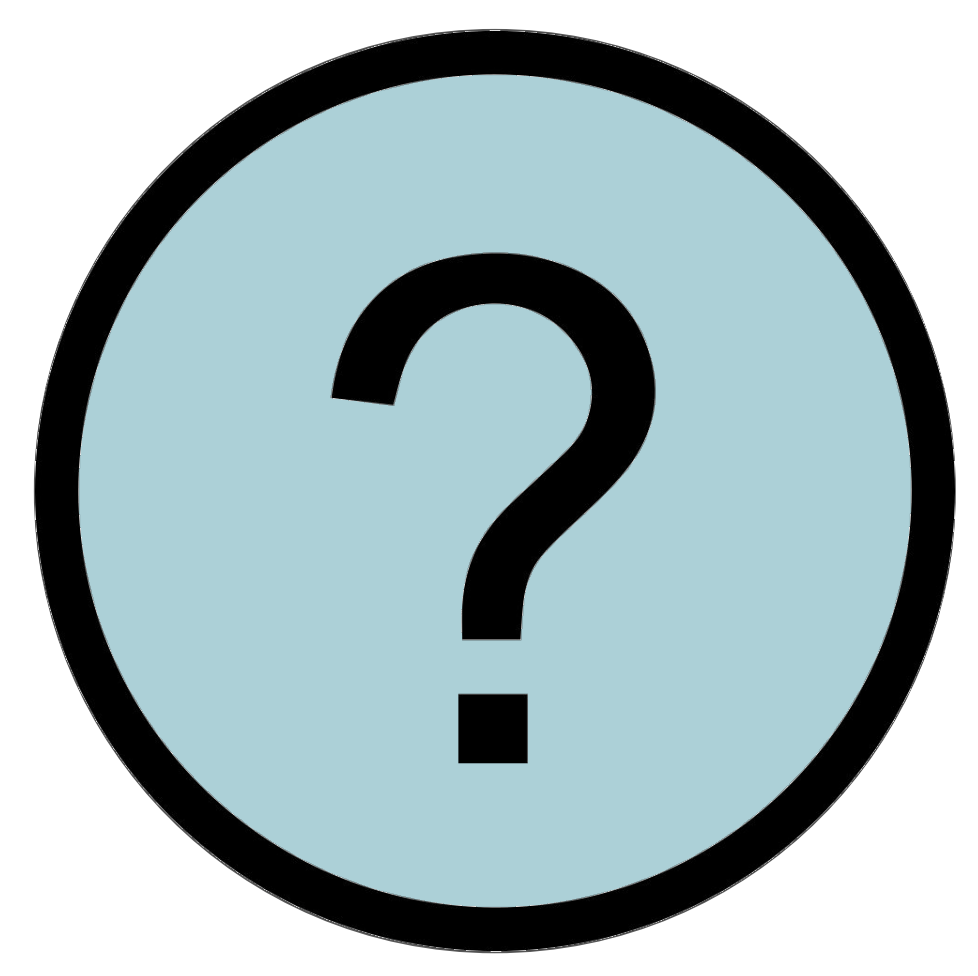

